\title{
COMMENTARY
}

\section{Tranexamic acid in cardiac surgery: is there a cause for concern?}

\author{
David Royston* \\ See related research by Sander et al., http://ccforum.com/content/14/4/R148
}

\begin{abstract}
The withdrawal of marketing approval for aprotinin resulted in more clinicians administering tranexamic acid to patients at increased risk of bleeding and adverse outcome. The latest in a series of retrospective analyses of observational data is published in Critical Care and suggests an increase in mortality, when compared to data from the aprotinin era, in those patients having surgery when a cardiac chamber is opened. The added observation of an increase in cerebral excitatory phenomena (seizure activity) with tranexamic acid has a known mechanism and questions if such patients should be given this drug.
\end{abstract}

A recent article from the group in Berlin [1] reports on a retrospective review of observational data comparing their experience using tranexamic acid as an enforced alternative to aprotinin. Their data suggest an increase in morbidity and mortality in the tranexamic acid treated patients. Is this a cause for concern and what does it mean for the future?

The voluntary withdrawal of aprotinin in certain markets has had two major effects. The first was to cause all of the safety and efficacy data for aprotinin to be independently examined by regulatory authorities in both North America and Europe. This process is coming to its conclusion and it is anticipated that, based on a positive benefit-risk ratio, the Canadian authority will renew the marketing license for aprotinin before the end of this year. The European agency is also starting a review [2] but it is not anticipated this process will be completed until 2011.

The second effect of the withdrawal of aprotinin was that clinicians had to find an alternative blood-sparing

*Correspondence: D.Royston@rbht.nhs.uk

Royal Brompton and Harefield NHS Foundation Trust, Harefield, Middlesex, UB9 6JH, UK agent for use during major cardiac surgery. The two alternatives are the lysine analogues epsilon aminocaproic acid and tranexamic acid. Epsilon aminocaproic acid has no approval in Europe or Canada for human administration, leading to the exclusive use of tranexamic acid in these countries.

This shift highlighted a number of problems concerning tranexamic acid. The first was to define an appropriate effective dose. There is only one study investigating a dose-response relationship [3]. This article showed a plateau effect on drains losses with a total dose of 3 grams tranexamic acid but with no observed effect on transfusions. The population studied were patients having lowrisk primary myocardial revascularisation. The second problem is that there is no evidence for a benefit of tranexamic acid to reduce transfusion burden in patients at higher risk for transfusions, such as those taking aspirin prior to surgery [4] and those having prolonged bypass periods associated with more complex, typically combined valve and revascularisation surgery. The current article [1] mirrors a meta-analysis showing reexploration for bleeding is reduced by aprotinin but not tranexamic acid in such patients [5]. Finally, and of crucial importance, there have never been any specifically powered studies to investigate the safety of tranexamic acid.

Over the past months a number of articles have suggested the use of tranexamic acid is not without risk. In an extension of a previous analysis from Toronto, the authors concluded that mortality after cardiac surgery other than primary revascularisation was greater in those patients given tranexamic acid compared to those given high dose aprotinin [6]. An increase in mortality when tranexamic acid was given instead of aprotinin is also a conclusion from the current article [1].

Neurological outcomes is a long standing safety concern as we know administration of tranexamic acid is associated with clinically significant cerebral vasospasm with acute cerebral haemorrhage [7]. The current article [1] shows a three-fold increase in patients having seizures who were allocated to receive high dose tranexamic acid as part of their management during surgery where a 
cardiac chamber was opened. Can this observation be causally associated with tranexamic acid administration?

The statistical analysis used in the current study was similar to that used to show a deleterious effect of aprotinin, which has subsequently been shown to be flawed. However, an analysis error seems less likely in this case for two reasons. First, a potential mechanism for altering the excitatory neuronal state is recognised. The lysine analogues have marked structural homology with gamma amino butyric acid (GABA) and act as competitive inhibitors in the central nervous system $[8,9]$. This inhibition is observed clinically as an increase in seizure activity $[9,10]$. Second, several other groups have independently made the observation of increased seizure activity, mainly in patients having open cardiac chamber procedures $[11,12]$.

What can and should happen next? The European regulatory authority is currently deliberating on not only the licensing for aprotinin but also tranexamic acid [2]. With the increasing body of evidence, it is becoming clearer that aprotinin therapy is of greatest benefit in patients at highest risk (the originally intended patient population [13]). The data also suggest that tranexamic acid in a dose of about 3 to 5 grams may be useful to reduce transfusion burden in patients not taking platelet active medication and having primary myocardial revascularisation. This patient population appears not to have observed safety issues when tranexamic acid was administered [5]. The current study adds to the data questioning if tranexamic acid administration has a place in higher risk cardiac surgery and especially in surgery where a cardiac chamber is opened.

\section{Competing interests}

In the past 5 years DR has acted as a paid consultant to Bayer Schering, Cubist and Curacyte, the pharmaceutical companies who have the potential blood-sparing agents aprotinin under review and Eccallentide and CU 2010 respectively under development.
Published: 6 September 2010

\section{References}

1. Sander M, Spies CD, Martiny V, Rosenthal C, Wernecke KD, von Heymann C Mortality associated with administration of high-dose tranexamic acid and aprotinin in primary open-heart procedures: a retrospective analysis. Crit Care 2010, 14:R148.

2. EMA [www.ema.europa.eu/pdfs/human/press/pr/10757010en.pdf]

3. Horrow JC, Van Riper DF, Strong MD, Grunewald KE, Parmet IL: The doseresponse relationship of tranexamic acid. Anesthesiology 1995, 82:383-392.

4. Mcllroy DR, Myles PS, Phillips LE, Smith JA: Antifibrinolytics in cardiac surgical patients receiving aspirin: a systematic review and meta-analysis. Br J Anaesth 2009, 102:168-178.

5. Henry D, Carless P, Fergusson D, Laupacis A: The safety of aprotinin and lysine-derived antifibrinolytic drugs in cardiac surgery: a meta-analysis. CMAJ 2009, 180:183-193.

6. Karkouti K, Wijeysundera DN, Yau TM, McCluskey SA, Tait G, Beattie WS: The risk-benefit profile of aprotinin versus tranexamic acid in cardiac surgery. Anesth Analg 2009, 110:21-29.

7. Fodstad H, Forssell A, Liliequist B, Schannong M: Antifibrinolysis with tranexamic acid in aneurysmal subarachnoid hemorrhage: a consecutive controlled clinical trial. Neurosurgery 1981, 8:158-165.

8. Barker JL, Nicoll RA, Padjen A: Studies on convulsants in the isolated frog spinal cord. I. Antagonism of amino acid responses. J Physiol Lond 1975, 245:521-536.

9. Furtmüller R, Schlag MG, Berger M, Hopf R, Huck S, Sieghart W, Redl H: Tranexamic acid, a widely used antifibrinolytic agent, causes convulsions by a gamma-aminobutyric acid(A) receptor antagonistic effect. J Pharmacol Exp Ther 2002, 301:168-173.

10. Feffer SE, Parray HR, Westring DW: Seizure after infusion of aminocaproic acid. JAMA 1978, 240:2468.

11. Martin K, Wiesner G, Breuer T, Lange R, Tassani P: The risks of aprotinin and tranexamic acid in cardiac surgery: a one-year follow-up of 1188 consecutive patients. Anesth Analg 2008, 107:1783-1790

12. Murkin JM, Falter F, Granton J, Young B, Burt C, Chu M: High-dose tranexamic Acid is associated with nonischemic clinical seizures in cardiac surgical patients. Anesth Analg 2010, 110:350-353.

13. Royston D, Bidstrup BP, Taylor KM, Sapsford RN: Effect of aprotinin on need for blood transfusion after repeat open-heart surgery. Lancet 1987, 2:1289-1291.

doi:10.1186/cc9227

Cite this article as: Royston D: Tranexamic acid in cardiac surgery: is there a cause for concern? Critical Care 2010, 14:194. 